\title{
Generational Basis of Turnout Decline in Established Democracies
}

\author{
Mark N. Franklin ${ }^{\mathrm{a}, \mathrm{b}}$, Patrick Lyons ${ }^{\mathrm{c}}$ and Michael Marsh ${ }^{\mathrm{d}}$ \\ ${ }^{a}$ Department of Political Science, Trinity College Connecticut, Hartford, CT 06106, USA. \\ E-mail: Mark.Franklin@trincoll.edu \\ ${ }^{\mathrm{b}}$ University of Amsterdam, Amsterdam, The Netherlands \\ ${ }^{c}$ University College, Dublin, Ireland \\ ${ }^{\mathrm{d}}$ Trinity College, Dublin, Ireland
}

Voting is a habit. People learn the habit of voting, or not, based on experience in their first few elections. Recent research has shown that elections that do not stimulate high turnout among young adults leave a 'footprint' of low turnout in the age structure of the electorate as many individuals who were new at those elections fail to vote at subsequent elections. Elections that stimulate high turnout leave a high turnout footprint. So a country's turnout history provides a baseline for current turnout that is largely set, except for young adults. This realization requires us to take a new approach to understanding the mainsprings of turnout change and hence of turnout decline. In this paper, we theorize about the longitudinal effects on turnout of changes in the character of elections, and test this theory using data from every one of the 22 countries that have held elections continuously since 1945: 356 elections in all.

Acta Politica (2004) 39, 115-151. doi:10.1057/palgrave.ap.5500060

Keywords: elections; voting; turnout; socialization; habitual voting; generational replacement

\section{Introduction}

Recent research into voter turnout has repeatedly demonstrated the importance of generational replacement in turnout change (Miller and Shanks, 1996; Lyons and Alexander, 2000; Putnam, 2000, 2002; Blais et al., 2001, 2004; Franklin and Wessels, 2002; Franklin, 2003, 2004). Turnout change, it appears, is led by the youngest members of the electorate who, as they age, become set in their ways at a level of turnout that may differ from the level demonstrated by earlier or later electoral cohorts. Two questions arise from this finding: (1) what is it that leads different generations to display different levels of turnout? And (2) in what ways do generational differences in turnout generate turnout change over time? In this paper, we address these questions employing data relating to all the elections conducted since World War II in all of the 22 countries that have conducted elections continuously since then. ${ }^{1}$ 


\section{What Makes Turnout Change?}

Although turnout change is not always in the downward direction, ${ }^{2}$ the tendency of commentators is to remark upon falling turnout rather than rising turnout, and to see such falls as indications of citizen disengagement and perhaps even disaffection (Teixeira, 1992; Dalton, 1999; Wattenberg, 2000, 2002; Patterson, 2002). The tendency to view turnout as a mark of support for political regimes is particularly marked among those who comment on falling turnout in European parliament elections (see especially Blondel et al., 1998) never mind the fact that falling turnout at such elections can be quite satisfactorily explained without recourse to measures of attitudes (Franklin, 2001) and that properly specified models of turnout at EU elections show no effects of attitudes toward Europe (Schmitt and Mannheimer, 1991; van der Eijk et al., 1996).

That high turnout should indicate regime support is not self-evident. In the early days of empirical social enquiry, those who studied turnout (Merriam and Gosnell, 1924; Gosnell, 1927; Boeckel, 1928; Tingsten, 1937) took it for granted that turnout would be higher when an election's outcome hung in the balance and when 'issues of vital concern are presented' (Boeckel, 1928, 517). Seen in this light, low voter turnout would be blamed on parties and politicians for failing to present issues of vital concern - or for failing to present such issues in an election where the outcome was seen as likely to determine the course of public policy. Thus, low voter turnout would have been blamed on the character of the election, not on the characters of those who failed to vote or their attitudes towards the regime.

It was the rational choice approach to explaining political behavior that changed our ideas about why people vote. Writing in 1968, Riker and Ordeshook, elaborating the ideas of Downs (1957), pointed out that the chances of any one vote affecting the outcome of an election for nation wide public office were virtually zero - even in a close race. For this reason, they went on to argue, people (unless they had quite unreasonable expectations about the importance of their vote) could not be voting with the purpose of benefiting from the outcome (Riker and Ordeshook, 1968, 28). Whatever the benefits any individual might receive as a consequence of policies adopted or blocked by an election's outcome, those benefits would be enjoyed whether the individual voted or not. So the only rational reason for an individual to vote would be in order to gain non-material benefits, such as the satisfaction of pulling one's weight and other aspects of civic virtue.

In the light of this argument, those who studied electoral participation in the years that followed paid little attention to benefits that might accrue to voters from the outcome of any specific electoral contest. Instead they focused on voting as a habit that people learned during their formative years - a learning 
experience dominated by education and social status. ${ }^{3}$ In their seminal work on Participation in America, Verba and Nie (1972) built their explanation of electoral participation on what they called a 'baseline model' consisting of income, occupation and education. This baseline model (later renamed the 'resource model') dominated explanations of individual turnout decisions in the United States and elsewhere until the present time (Wolfinger and Rosenstone, 1980; Parry et al., 1992; Rosenstone and Hansen, 1993; Verba et al., 1995). In recent research, the resource model has been joined by a 'mobilization model' that takes account of the fact that people also vote because they are mobilized to do so by parties, interest groups and candidates (Rosenstone and Hansen, 1993; Verba et al., 1995). But in all this work the focus for explaining why people vote is centered on the individual and things that happen to the individual rather than (as in earlier research) on the election and things about the election. ${ }^{4}$ In the light of this focus, it is not surprising that commentators should take low or declining turnout to be a reflection on the capacity and motivation of individual citizens.

Yet the idea that declining turnout is due largely to 'something about citizens' runs counter to some very obvious facts. In the first place, turnout varies from election to election both up and down; and while it is possible to imagine secular trends in civic virtue, it is hard to imagine what would cause it to fluctuate both up and down from election to election. Moreover, if it was civic virtue that drove turnout, why does virtue have more effect in some elections (US presidential elections, for example) than in others (US midterm elections, for example)? The same citizens vote in a presidential election who fail to vote at the following midterm election. Presumably it is not something about those citizens that makes them more likely to vote in certain elections than in others.

In the second place turnout varies enormously between countries. There are countries (like Australia, Belgium and Malta) where virtually everyone votes. If high turnout is due to 'something about citizens' then how come the citizens of these three countries are so different from the citizens of the United States and Switzerland (two countries where turnout in national elections is particularly low)? It is true that in Australia and Belgium voting is compulsory, but the law that makes abstention illegal does not affect the character of those countries' citizens. On the contrary, what it affects is the character of elections in those countries; and, if compulsory voting can affect voter turnout, then perhaps other things about the character of elections can also affect voter turnout. Voting is not compulsory in Malta, so (unless we want to assume that Maltese citizens are uniquely civic-minded) it seems clear that there must be at least one other feature of elections' character that can bring about universal turnout - or perhaps a combination of several features. 
Research at the aggregate level has in fact shown that a quite large number of things about elections affect turnout levels (Powell, 1980, 1982, 1986; Jackman, 1987; Crepaz, 1990; Jackman and Miller, 1995; Franklin, 1996, 2002; Blais, 2000; Norris, 2002). Indeed, Franklin (1996) showed that country differences in the character of elections had effects on turnout that were four times as great, on average, as individual-level differences. These differences give rise to two obvious components: costs (generally established by institutional features of each country, which are largely set in the short term - cf. Blais, 2000) and benefits (generally arising from the political situation and encapsulated in electoral competitiveness that varies from election to election - cf, Franklin, 2002). Changes in each of these components have very different implications for the evolution of turnout over time, as we will see.

This paper has two objectives. The first is to build on recent findings about the generational basis of turnout change in order to derive expectations for the way in which changes in the character of elections can be expected to manifest themselves in turnout change over time. The second is to test hypotheses deriving from these expectations in order to explain changes (generally declines but sometimes increases) in turnout over time in the 22 countries that have held elections continuously since World War II. We need to study elections held continuously because if any elections are missing we can neither investigate cumulative effects, nor influences like the habit of voting that are coded with reference to past elections. Many countries that started holding elections shortly after World War II do not meet the criterion of continuous elections. ${ }^{5}$ If we attempt to increase the number of countries beyond 22, we dramatically shorten the total period over which we can make the comparisons. At the same time, the period cannot be extended to include years before World War II because so many countries had at least two electoral cycles without elections before and during that singular cataclysm. The period of our study ends in 1999 because data for some variables are hard to find for elections more recent than that.

We study elections to the lower house of the national legislature in each country. We do not study presidential elections (where they occur) or midterm elections in the United States. Doing so would increase the weight of certain countries and might introduce anomalies if such elections do not respond to the same forces as elections to the lower houses of other national legislatures.

The overall evolution of turnout in these countries is displayed in Figure 1, which shows a rise from the early 1950s through to the late 1960s, followed by a decline that appears to be continuing (though too much should not be made of a decline of only 6 or 7 percentage points, as demonstrated graphically by the almost flat upper line in Figure 1). 


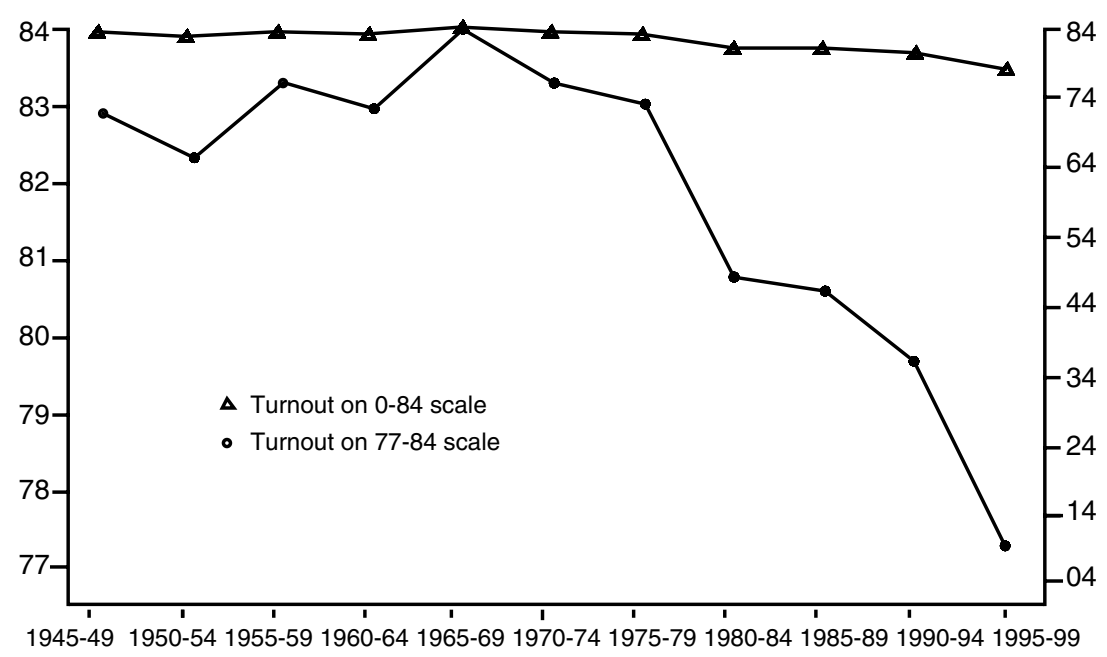

Figure 1 Average turnout in 5-year periods for 22 countries, 1945-1999.

\section{What Causes Generational Effects on Turnout?}

The idea that generational replacement plays a role in turnout change is one that has not been extensively explored in the literature. Newly enfranchised individuals are known to be particularly open to recruitment by new parties and to be largely responsible for such changes as occur in the support for existing parties (Campbell et al., 1960; Butler and Stokes 1974; Nie et al., 1976; Inglehart, 1977, 1990, 1997; Rose and McAllister, 1990; Franklin et al., 1992; Franklin and Ladner, 1995; Miller and Shanks, 1996). The same importance of newly enfranchised individuals has been found in regard to turnout (Miller and Shanks, 1996, Lyons and Alexander, 2000; Putnam, 2000, 2002; Blais et al., 2001; Franklin and Wessels, 2002; Franklin, 2003; Blais et al., 2004): change in turnout most often comes from a new cohort of voters turning out at a rate that is different from the turnout rate among the previous cohort when they were new. ${ }^{6}$

Newly enfranchised individuals are also known to rapidly become immunized against changing their minds if they support the same party at even a quite small number of consecutive elections (Butler and Stokes, 1974). The implications of this last insight for turnout change have only recently started to be explored (Franklin and Wessels, 2002; Franklin, 2003, 2004), although it may well supply an explanation for the fact that it took fifty years after female suffrage for the gender gap in US turnout to be eliminated (Christy, 1987; Norris, 2001). The explanation for this delay would focus on 


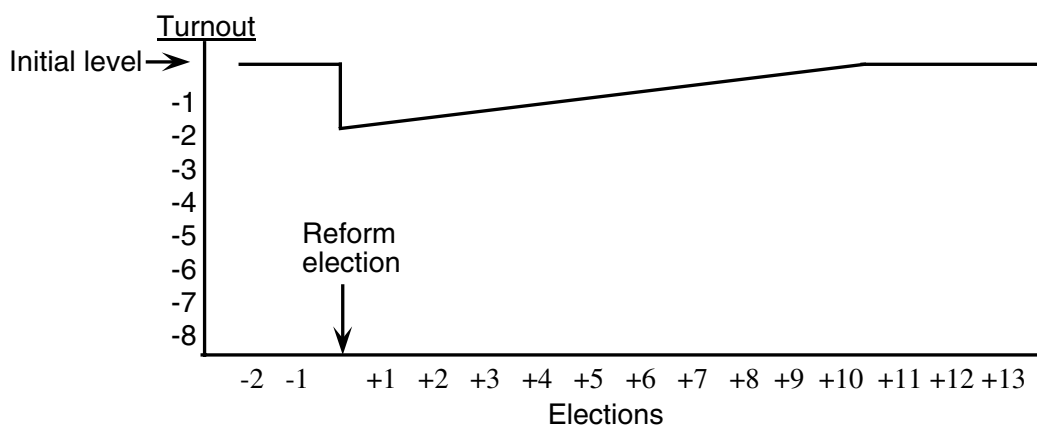

Figure 2 Expected long-term evolution of turnout following extension of franchise to a previously disenfranchised group.

the fact that only women who had not yet learned the habit of non-voting would have taken full advantage of a franchise extension when it occurred. New female voters, as they entered the electorate after the extension of the franchise, would learn the habit of voting at the same rate as men, but it might take as much as 50 years for the last of those socialized before the franchise extension to leave the electorate (see Figure 2), explaining the slow rise in female turnout that has puzzled scholars (Norris, 2001). Similar processes will presumably also have been at work following other franchise extensions in the US and elsewhere.

In a paper delivered at the American Political Science Association (Franklin and Wessels, 2002), it was suggested that a particularly intriguing implication of the responsiveness of incoming cohorts to changes in the character of elections arises from the lowering of the voting age to 18 in many countries during the 1960s and 1970s. That paper argued, following Plutzer (2002), that voting is costly and that the costs of learning to vote are considerably raised if a person's first election falls during the period immediately after leaving high school. In most countries, people leave high school at about 18 years of age. The 4 years that follow are fraught with the problems of early adulthood. More importantly, those 4 years are years in which young adults are only starting to establish the social networks that will ultimately serve to guide their political choice and motivate their vote (Plutzer, 2002). So the costs of learning to vote, high at any age, might well have been measurably increased by the lowering of the voting age, leaving a footprint in the electorate of lower turnout that would expand with the (younger) coming of age of each new cohort - a process we will refer to as 'young initiation' (see Figure 3 ). ${ }^{7}$ Such a process would explain gradually declining turnout in every country that lowered the voting age (generally from 21 to 18) during the final decades of the 20th Century. 


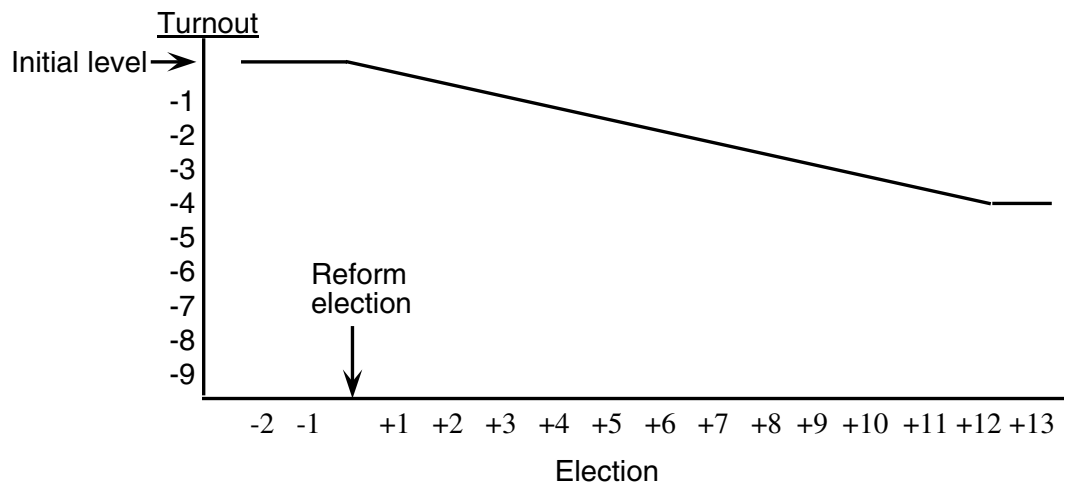

Figure 3 Expected long-term evolution of turnout following an extension of the franchise to younger voters.

A third type of generational effect is more straightforward. The abolition of compulsory voting, or the introduction of postal voting, or any other change in the 'rules of the game' that surround the voting act will primarily affect new cohorts - those who are not already set in the habits of voting or non-voting. But as long as the new rule remains in force, the passage of time will bring additional cohorts into the electorate who will vote at the rate made possible by the new rule. At the same time, older cohorts will be dying off. So turnout will progressively change from the level pertaining before the new rule took effect to the level found among new cohorts after the rule took effect. Eventually, after about 50 years, the entire electorate will have been replaced with cohorts socialized under the new rule, and turnout will stabilize at the level initially found only among new cohorts (see Figure 4). A generational basis of turnout change in response to institutional change could resolve a number of puzzles regarding turnout change, especially the long-term fall in turnout in the Netherlands and Switzerland, together with the absence of immediately apparent consequences of institutional change in Italy, Japan and New Zealand.

One critical question that must be answered before we can understand how generational change in turnout will work out in practice is how many years does it take for an electoral cohort to become socialized into a particular level of turnout? Butler and Stokes (1969, 1974), when studying party choice, suggested that it was not so much the number of years as the number of elections that counted: each election provided voters with the opportunity to reaffirm their electoral decision, or not. If their decision was reaffirmed each time, all it took was three elections to establish the habit of voting for a particular party. 


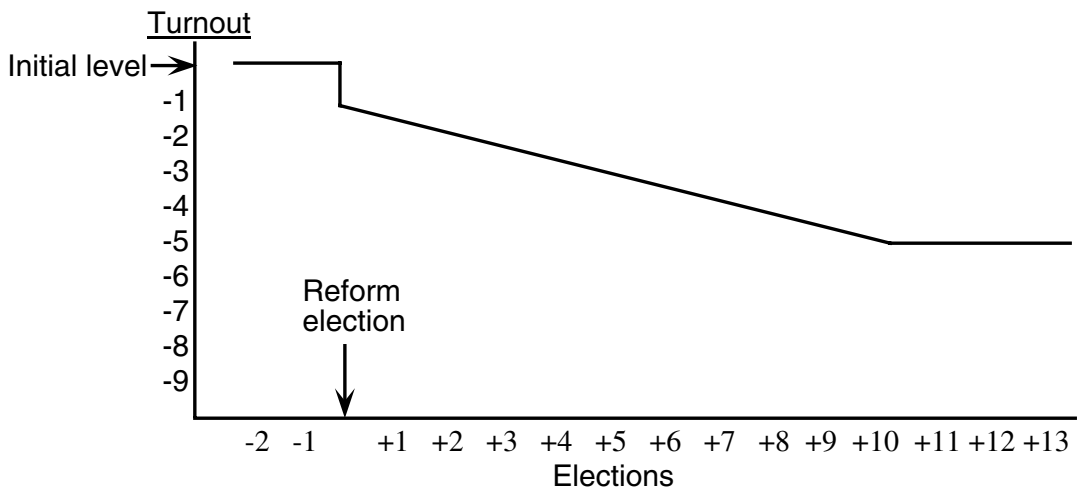

Figure 4 Typical expected long-term evolution of turnout following a change in election law.

In the paper already referred to, Franklin and Wessels (2002) showed that, in the six countries for which we have survey-based election studies for every election going back to the 1960s (Britain, Germany, Netherlands, Norway, Sweden and the United States), three elections appeared also to be the number it took to establish the habit of voting or non-voting. Volatility in turnout for electoral cohorts in all these countries was markedly less after three elections than over the course of the first three elections (see Franklin (2004) for a more elaborate analysis). So a change in the character of elections of a once-only kind (the introduction or abolition of compulsory voting, for example) will cause a change in turnout among the youngest three cohorts, followed by a gradual amplification of the change as additional cohorts join those three.

But note a clear implication of the above summary: any feature of the character of elections that changes repeatedly (especially if those changes are random in direction and magnitude) will not engage the socializing process that gives rise to generational effects. This means that we must distinguish between two different types of effect on turnout: long-term, or cumulative, effects that involve a progressive shift in turnout in one direction, and short-term effects that cause turnout to fluctuate about the (perhaps changing) long-term norm.

Figures 2-4 were drawn assuming effects of similar magnitude. Figures 3 and 4 show an overall drop in turnout of 5 percentage points. However, an effect of similar magnitude resulting from female enfranchisement (in Figure 2) only causes an initial fall in overall turnout of some 2 percentage points, since that extension of the franchise affects only about half the individuals in the electorate (and some of these adapt immediately to their change in circumstances). The drop is then eroded over the following 10 elections. ${ }^{8}$ There is of course no good reason to suppose that the various effects would be 
of similar magnitude, and the actual magnitudes of these effects do not have to be assumed. They will be discovered empirically. However, the three different cumulation functions are theoretically determined. The only confirmation we will get that the evolution of turnout follows the three different patterns shown in Figures 2-4, depending on the type of reform concerned, will be that the resulting variables yield plausible findings and that the pattern of predictions we make with the help of these functions matches the pattern of turnout change observed empirically in each country.

The graphs are also constructed on the assumption of uniform cohort size, but this assumption is made only for the sake of providing an idealized picture of the expected consequences for voter turnout of different kinds of electoral reform. In practice we will be able to take account of changes in the sizes of incoming cohorts provided we are able to keep track of these changes. Indeed, to evaluate the effects anticipated in Figures 2-4 we need to be able, for each electorate, to keep track not only of the sizes of incoming cohorts but also of the evolving size of the group that consists of the newest three cohorts taken together. And of course we need to know the total size of the electorate as this evolves over time, since the important quantities are the sizes of incoming and impressionable cohorts as proportions of the size of the entire electorate in each country. None of these quantities are straightforward to determine. The method we employ is detailed in the appendix.

\section{Research Strategy}

Our primary interest is in exploring the influences on turnout of various features of the character of elections - features that relate to the utility of voting which we believe to be the primary motivating forces that drive voter turnout. In addition to features that are strictly electoral (the type and proportionality of the electoral system, the extent of the franchise, whether absentee ballots are permitted, whether voting is compulsory, and district magnitude) we will consider aspects of an election's character to include how much time has elapsed since the previous election, whether an election is held on a working day or at the weekend, the closeness of the race (both overall and on average across the districts or constituencies of countries with majoritarian electoral systems), the size of the electorate, ${ }^{9}$ the proportion of the electorate made up of new cohorts, the size of the largest party (seen in terms of how far it is from having the power to carry its policy proposals into law), the cohesiveness of parties in the legislature (the extent to which party discipline is maintained), their polarization (the extent to which their election manifestos make different appeals), and the responsiveness of the executive to changes in the balance of legislative forces. Because such a large proportion of the 
electorate are assumed to have made a standing decision to vote or not to vote, we also need to include a measure of inertia - a surrogate for the character of elections past (which we will indicate by the level of turnout at earlier elections). ${ }^{10}$

These variables are almost all of them taken from past research (especially Blais, 2000; Franklin, 2002; Norris, 2002). The only one that has a new twist is the responsiveness of the executive - a variable taken from Banks (1997) that indicates the extent to which a country's executive is answerable to the Parliament. It replaces the Swiss and US dummy variables used in past research to indicate elections of low salience in these countries, but goes further in accounting for increased turnout in Malta in recent years as well as other idiosyncratic elections (Franklin, 2004). We have well-established expectations for the direction of effects to be expected from all of these variables, so we can test for significant effects using one-tailed tests.

Operationally, the important distinction to be made is between variables that have their effects mainly on new cohorts - which we refer to as short-term factors - and variables whose effects on new cohorts are amplified by being repeated for cohort after cohort, eventually affecting the entire electorate which we refer to as cumulative factors. Among the variables listed above, only absentee ballots, compulsory voting, extent of the franchise, size of the electorate, average district magnitude, and responsiveness of the executive are cumulative in nature; ${ }^{11}$ though the extent of the franchise provides us with two variables: one concerned with the lowering of the voting age and one concerned with (generally earlier) extensions of the franchise to women. The remaining independent variables change their values frequently enough (not in general retaining the same value for four elections or more) to yield only short-term effects. $^{12}$ Since most short-term effects involve electoral competition, as does executive responsiveness, the model can be viewed as one that focuses on electoral competition as the primary driving force determining turnout levels.

Both short-term and cumulative effects are quite easy to operationalize provided we have a measure of the proportion of the electorate that falls within the scope defined as 'new cohorts' (those facing one of their first three elections). ${ }^{13}$ That proportion can be used to weight the changing values of the variables concerned, creating an interaction between each of the various measures of short-term forces and the proportion of the electorate upon which those forces are expected to operate most strongly. Changes in turnout can be expected to reflect both components of this interaction, occurring either when the substantive variable changes its value or when there is a change in the proportion of the electorate affected by the influence concerned - and especially when a large change in some factor coincides with a period when a large proportion of the electorate is responsive to such changes. Thus, for 
example, the closeness of the race at a particular election will matter more when more potential voters than usual are members of new cohorts. ${ }^{14}$

To measure cumulative effects we also need a measure of the proportion of the electorate affected by short-term factors. But, for the long-term factors, we are interested in the cumulative proportion of the electorate that was exposed to the changed influence during its formative years. Indeed, the only difference between short-term and cumulative factors is that short-term factors change their values before having had the chance to generate cumulative effects. Both have their effects primarily on new cohorts, so an accurate measure of the size of new cohorts is critical to our research strategy (see the appendix).

Since the size of the group consisting of new cohorts is a proportion bounded by 0 and 1 it follows that, when this proportion is multiplied by a substantive variable to generate an interaction term, the interpretation of coefficients for that interaction term is the same as whatever interpretation would have been made of coefficients for the substantive variable without interaction. The effect measured by such an interaction can be viewed as the effect on members of the group concerned (the smaller the group, the more the coefficient for the interaction is boosted; when the group constitutes the whole of the electorate the interaction involves a multiplication by 1 and the resulting coefficient is unchanged). The effect measured for such an interaction can also be viewed as the effect the variable would have if everyone in the electorate had been exposed to its influence during their formative years. ${ }^{15}$

To ease interpretation and comparison between coefficients, with two exceptions all variables have been scaled either as percentages or as proportions. The dependent variable, turnout, is measured in percentages, so all other figures related to votes are also measured in percentage terms. Measures relating to features of elections are generally dummy variables or proportions that vary between 0 and 1 ( 0 and -1 , for convenience, in some cases). So variables with other scales have been reduced to a scale with a 1-point difference (often -0.5 to +0.5 ). ${ }^{16}$ The exceptions are executive responsiveness and electorate size. Responsiveness is measured on a four-point scale but most countries never move by more than one point on this scale. When considering effects of changing executive responsiveness in Switzerland the coefficient must be multiplied by 4 , the number of points by which executive responsiveness was reduced in Switzerland after 1959 (Franklin, 2004). Electorate size is measured in millions.

In the case of extensions of the suffrage to women, our interest is not so much in the amount that turnout was depressed when the franchise was extended, since for most of our countries this happened long before the start of our period, but in the extent to which the presumed causes of lower turnout among women have been mitigated through the replacement of older women 
with women socialized after receiving the right to vote. For this reason, we refer to the variable concerned as 'female empowerment' and the interaction of female empowerment with the proportion of women who had the opportunity to vote while still of an impressionable age is the effect that will pertain when all women have had that opportunity. ${ }^{17}$ This coding has two consequences. In the first place, the effect should be positive, precisely because extensions of the suffrage to women will have caused a fall in turnout which, over time, will have been eroded as successive cohorts of women learned the habit of voting (Figure 2). In the second place, any extension of the franchise to women that actually occurs after the first election in our data for the country concerned (notably in Switzerland in 1972) will generate a large negative value for this variable. Female empowerment is low in the first election after the extension of the franchise to women, dragging overall turnout down in consequence. Values of this variable become progressively less negative as female empowerment grows over the years that follow.

By contrast, in the case of extensions of the franchise to 18-year-olds, we expect the effect to become gradually more negative. This is because the process of giving to all of those who first vote at 18 a worse experience of their early elections than they would have had at a later age (Franklin and Wessels, 2002) should generate a fall in turnout - a fall that should grow larger as the size of this group grows to encompass the entire electorate (Figure 3 ). It is the experience of being initiated into the political world at a younger age that is responsible for the effect, and for this reason we refer to the variable as 'young initiation.'

It is logically possible for a variable to have both cumulative and short-term effects, if it changes its value repeatedly in some countries but not in others; or if variations occur around means that are very different at different times. So it is logically possible for measures of both short-term and long-term effects for the same variable to prove significant. It is also possible for the original substantive variables to prove significant, which would imply effects that are not differentiated according to whether voters are established or not. If such variables were to prove significant, this could mean one of two things. If the variable were constant over time but differed as between countries, it could be indicating effects ('super long-term' effects) due to processes that were completed prior to the start of our data. Significant effects in any other circumstances would put the entire theoretical basis of this research into question - unless there are obvious reasons applying to specific variables that would account for the anomalies.

Because all of these variables derive in one way or another from the sizes of new cohorts, they are going to be quite strongly related. So multicollinearity could be a concern in any analyses that employ them. But, more importantly, the dependence of so large a number of variables on the accuracy of a common 
component gives us a large stake in how that component is measured (see the appendix).

\section{Estimation issues}

Estimating the effects of these independent variables on the level of turnout in established democracies is complicated by the nature of the data. Not only does it contain variation over time, with between 13 and 22 elections in each country, but also variation over space, with 22 different countries. To deal with interlocking sources of variation such as these, a plethora of different estimation procedures focus on different aspects of this variation in different ways. In this section, we will discuss the estimation problem in general terms and introduce the procedures that will later be used in attempting to do justice to the hypotheses investigated in this paper.

To employ a sequence of national elections in each of a set of countries, we need to address two methodological issues. The first arises from the fact that the amount of variance in turnout differs greatly as between countries. Some countries see a virtually constant level of turnout whereas others see large changes in level, while still others see fluctuations about a relatively constant level. This suggests the likelihood of problems arising from estimation errors. When poorly estimated cases are not randomly distributed (a condition known technically as heteroskedasticity) this can result in inefficient estimates (Greene, 1990, 416-418). The second issue is how to allow for the fact that voter turnout tends to retain much the same level over time in the same country, so that turnout at any given election can be quite well predicted from turnout at the previous election (a condition known technically as time-serial dependency). Such dependencies could result in correlated error terms and biased regression coefficients. (Maddala, 1988, 206-207).

Starting with at the problem of possible heteroskedasticity in the data, in the first instance we attempt to solve this by choosing a model that manages to fit country differences in turnout variations, and one of our concerns will be to see how successful we have been in this. ${ }^{18}$

Two classes of approach exist for dealing with time-serial dependencies. The first approach attempts to adjust the coefficients so as to remove what is regarded as contamination due to what is referred to as an autoregressive (or AR1) process, and so 'clean up' the error term. When this has been satisfactorily achieved, the result is a set of so-called panels of cases, one panel for each country, consisting of replications of that country whose variables are measured repeatedly with randomly distributed error. This approach considers the time serial dependencies as giving rise to non-random errors and tries to remove those errors. Even after removing the time-serial 
dependencies, however, the set of cases that constitute each panel are probably more like each other than they are like cases from other panels, giving rise additionally to the need for 'panel corrected' standard errors (Beck and Katz, 1995).

The problem of possible time-serial dependencies can also be addressed by modeling them explicitly - including among the predictor variables one or more that measure the source of the dependency (Beck, 2001; Katz, 2001). This approach specifies the expected contamination in the data instead of letting it fall into the error term. We have already made it clear that we expect turnout at earlier elections to have an effect on turnout at the current election by way of the habit of voting or non-voting, so this approach is attractive. But using as an independent variable, a lagged version of the dependent variable can result in inflated variance explained. ${ }^{19}$ It can also depress estimates of the effects of other independent variables (Achen, 2000).

Because we expect a time-serial dependency in our data (due to habits of voting and non-voting), any technique that treats such dependencies as errors to be purged will not suit the research question addressed in this paper. Moreover, omitting a lagged dependent variable that is called for theoretically may inflate the effects of other independent variables, due to exactly the same logic as leads one to eschew the use of a lagged dependent variable that is not called for theoretically. Specifically, omitting this variable could result in too much weight being given to other variables that also predict stability (those that change little over time).

However, incorporating past turnout brings with it a strong presumption of bias in the resulting estimates (Kennedy, 1992, 142) - a bias that comes from using a version of the dependent variable as though it were independent. This bias can be purged by employing a two-stage estimation procedure that replaces lagged turnout by a so-called instrumental variable that derives its values from the values of other independent variables that have also been lagged and are thus measured contemporaneously (Kennedy, 1992, 143). It will be seen that estimated effects of the character of elections are indeed quite sensitive to whether or not we include a lagged measure of turnout, but whether or not that lagged variable is instrumented will be seen to matter much less. It also does not seem to matter whether we consider our data as constituting a panel of independent cases for each of 22 countries or as a set of 22 separate time series. ${ }^{20}$

Nor does it matter much in practice how we enforce a focus on the over-time variability in the data at the expense of cross-country variability. A classic method of achieving this end (Cohen and Cohen, 1983), still widely employed by political scientists, is to include among the predictors a dummy variable for each country (except for a base country whose dummy is omitted). The same possible objections can be raised to this method as have been raised regarding 
the use of a lagged dependent variable: dummy variables to control for country differences might raise variance explained while depressing the effects of substantive variables. The alternative is statistically cleaner. This is to transform the data so that each variable is expressed in terms of its deviation from the mean for that variable in each country. This entirely removes country differences from the data, leaving (in our study) 22 separate time series rendered comparable by being transformed onto the same scales (though it might still be necessary, additionally, to remove country differences in the variance of each variable should heteroskedasticity prove problematic in the manner discussed earlier). The trouble with this approach is that variables that had already produced their long-term consequences before the start of the time-period covered in our data would have no opportunity to demonstrate their importance. Myopically focusing on variance occurring during a specific period (even a period that extends for half a century) could arbitrarily exclude influences that were felt before the start of that period.

In what follows, we will employ both methods of enforcing a focus on overtime variability. The first method will be used to tell us whether there are significant country differences in turnout attributable to settled features of the character of elections that differ between countries, and the second method will be used to make the best possible estimates of the effects of over-time variations in independent variables. We will also demonstrate, however, that it makes little difference to parameter estimates which method is chosen; nor whether country differences are eliminated through the inclusion of country dummies or by taking our variables in terms of deviations from country means. $^{21}$

\section{Hypotheses}

The hypotheses we can address with these data derive from the outline given earlier of the expected trajectories of turnout change that would result from a generational basis for turnout evolution. Based on the notion that changes in the value of an independent variable had to be at least semi-permanent (last for at least four elections) in order to have cumulative effects, we expected cumulative effects from only a small number of developments. These were the reduction of the voting age (in most countries), the removal of compulsory voting (in the Netherlands in 1971 and in Italy in 1994), the introduction of absentee voting (in Canada in 1972, Finland in 1970, and Switzerland in 1995) or its removal (in France in 1978), the loss of a cohesive party system (in Belgium in 1961 followed by its recovery four elections later), executive responsiveness, the introduction of female suffrage (in Switzerland in 1971, Belgium and Italy in 1948, Japan and France in 1946, and other countries at 
various dates prior to the first election in our data set), ${ }^{22}$ average district magnitude, and the sizes of electorates (the last two of which were both prone to successive increases over the course of the period under study). Other variables were presumed to have only short-term effects as already explained.

Where it was possible to do so (in the case of absentee voting, party cohesion, electorate size, and average district magnitude) both short-term and cumulative effects were measured, and for every variable the original version was tried in addition to short-term and/or cumulative versions. Effects of such variables would be interpreted as effects on all voters — 'super long-term' effects that only manifest themselves as country differences. We do not expect electoral characteristics that vary over time to affect all voters (see H5 below). ${ }^{23}$

Our resulting hypotheses are as follows:

H1: We expect significant effects from the following variables operationalized as short-term factors: time since the previous election, weekend voting, majority status of the largest party (how close to receiving 50\% of the votes), margin of victory of the largest party, mean margin of victory across the districts in majoritarian systems (coded 0 for nonmajoritarian systems), polarization and cohesion of the party system, decisiveness of the election, and disproportionality of the electoral system.

H2: We expect significant effects from the following variables operationalized as long-term factors: compulsory voting, absentee voting, female empowerment, extension of the franchise to 18-year-olds, size of electorate, average district magnitude, and responsiveness of the executive to the political complexion of the legislature.

H3: We expect a significant effect of past turnout.

H4: We do not expect any features of the character of elections that can vary over time (other than past turnout) to prove significant except when operationalized as a short-term or cumulative factor.

H1 mainly involves electoral competitiveness, $\mathrm{H} 2$ mainly involves processes of generational replacement, and $\mathrm{H} 3$ involves inertia.

\section{Preliminary Analyses}

Each independent variable can exist in as many as three versions if it made sense to calculate both cumulative and short-term versions in addition to the original (uninteracted) version. These different versions were tested against each other in a large number of preliminary analyses (not shown) in order to 
determine whether our expectations would be confirmed regarding which version was appropriate. $^{24}$

On the basis of preliminary analyses, we found only one variable that performed better in its original form than in cumulative or short-term interactions. This was time since the previous election. This variable appears to act about equally on all citizens regardless of whether they are members of established cohorts or of new cohorts, in defiance of H4. That hypothesis was evidently overstated when it was taken to apply to all variables. When two legislative elections are held in close proximity (generally because a coalition government could not be formed on the basis of the outcome of the first election but sometimes because a minority government or a government with a bare majority hoped to improve its position) this appears to reduce the turnout of all cohorts, established as well as new. We will address the theoretical implications of this anomaly later in the paper.

Of considerable significance is the failure of any other simple variable to work better than the same variable in appropriate interaction. This means that variables such as weekend voting that might have obtained their cross-country significance from long-term effects that occurred prior to the start of our period, do not appear to have done so.

\section{Findings}

Table 1 contains three models showing the effects on turnout of all variables found significant in any of these models. ${ }^{25}$ The three models show the effects that derive from estimation procedures that retain cross-country effects: GLS regression models with panel corrected standard errors that are further corrected for time serial dependencies. Model A has no lagged variable or country dummies. Model B operationalizes the role of inertia by bringing a lagged variable into play (turnout at previous elections). Model $\mathrm{C}$ further adds dummy variables for all of the 22 countries included in the data, except for Finland (the country which deviates least from the turnout predicted by the model). ${ }^{26}$

Of these models, Model B's effects appear to vindicate Achen's (2000) warning that incorporating a lagged dependent variable could reduce the effects ascribed to other variables. Model B's effects are often considerably lower than in Model A - sometimes implausibly low. Interestingly, however, these underestimates are not echoed in Model $\mathrm{C}$ where country dummies are included. That model is the one that employs the method customary in political science for handling data of the kind analyzed in this paper (time series panel data). It also has the most plausible coefficients of the three models, with statistically significant effects of all the independent variables except for 
Table 1 Three models explaining turnout in 22 countries, 1945-1999, using AR1 correction for autocorrelation (panel corrected standard errors in parentheses)

\begin{tabular}{|c|c|c|c|}
\hline Variable (range of values) & $\begin{array}{c}\text { Model } A \\
P C S E^{\mathrm{a}} \text { basic }\end{array}$ & $\begin{array}{c}\text { Model B } \\
\text { PCSE }^{\mathrm{a}} \text { with lag }\end{array}$ & $\begin{array}{c}\text { Model C } \\
\text { PCSE }^{\mathrm{a}} \text { with dummies }\end{array}$ \\
\hline Time since previous election in years $(0-7)$ & $0.54(0.16)^{* * *}$ & $0.69(0.18)^{* * *}$ & $0.64(0.18)^{* * *}$ \\
\hline Short term majority status $(0-17)$ & $-0.52(0.15)^{* * *}$ & $-0.43(0.08)^{* * *}$ & $-0.40(0.09)^{* * *}$ \\
\hline Short term margin of victory $(0-10)$ & $-0.48(0.15)^{* * *}$ & $-0.24(0.11)^{*}$ & $-0.36(0.13)^{* *}$ \\
\hline Short term mean margin $(0-10)$ & $-0.28(0.32)$ & $-0.14(0.18)$ & $-0.67(0.26)^{* *}$ \\
\hline Short term cohesiveness $(0-0.6)$ & $9.97(2.80)^{* * *}$ & $3.76(1.69)^{*}$ & $7.74(2.16)^{* * *}$ \\
\hline Cumulative compulsory voting $(-1$ to 0$)$ & $12.30(0.89)^{* * *}$ & $1.78(0.77)^{*}$ & $12.90(3.66)^{* * *}$ \\
\hline Cumulative absentee voting $(-0.5$ to +0.5$)$ & $3.30(1.06)^{* * *}$ & $1.13(0.56)^{*}$ & $-1.52(1.71)$ \\
\hline Cumulative executive responsiveness $(-1$ to +2$)$ & $7.86(1.00)^{* * *}$ & $0.76(0.55)$ & $4.60(0.82)^{* * *}$ \\
\hline Cumulative female empowerment $(0-1)$ & $6.63(5.06)$ & $-1.27(2.54)$ & $5.19(2.69)^{*}$ \\
\hline Cumulative electorate size (millions) & $-0.07(0.02)^{* *}$ & $-0.01(0.01)$ & $-0.05(0.01)^{* * *}$ \\
\hline Cumulative proportion of young initiation $(0-0.82)$ & $-4.66(1.90)^{* *}$ & $-2.35(0.96)^{* *}$ & $-3.94(1.05)^{* * *}$ \\
\hline Previous turnout $(41-98)$ & & $0.86(0.05)^{* * *}$ & $0.34(0.08)^{* * *}$ \\
\hline Constant & $81.56(2.35)^{* * *}$ & $11.80(4.06)^{* *}$ & $55.36(7.47)^{* * *}$ \\
\hline$N$ of cases & 334 & 334 & 334 \\
\hline$R^{2}$ & 0.72 & 0.91 & 0.94 \\
\hline Breusch-Godfrey autocorrelation test (3 df) & $12.29 * * *$ & $4.96^{* * *}$ & 0.42 \\
\hline Arch test for heteroskedasticity ( $3 \mathrm{df})$ & $8.87 * * *$ & $2.37^{*}$ & 1.51 \\
\hline
\end{tabular}

${ }^{\mathrm{a}} \mathrm{PCSE}=$ panel corrected standard errors.

${ }^{b}$ Includes dummy variables for all countries except Finland (effects not shown).

Note: Significant at $* 0.05 ; * * 0.01 ; * * * 0.001$ (one-tailed). 
absentee voting. Moreover, the effects in Model $\mathrm{C}$ are generally closer to those shown in Model A, the model without a lagged variable, than to those in Model B where the use of a lagged dependent variable appears to have had biasing effects. Finally, Model $\mathrm{C}$ is well behaved in that the tests for autocorrelation and heteroskedasticity, whose results are given in the table, prove not significant.

One final feature of these models should be especially noted. The only independent variable that proves significant in its raw form is time since the previous election (as already mentioned). All the other independent variables with significant effects are variables operationalized as either short-term or cumulative factors, largely confirming the fourth hypothesis listed above.

Although Model C tries to deal with country effects by including them in the model, we argued earlier that a better method for achieving this is to recast the analysis in terms of deviations from country means. Table 2 contains three models whose variables (both dependent and independent) have been transformed in this way (technically these are known as 'fixed effects' models). These contain no cross-country variation so dummy variables are not needed to account for such variation. Included are, once again, only variables that prove significant in one or more of the models (see Note 25). Again, the first model (Model D) includes no lagged version of the dependent variable and the other models (Models E and F) do include such variables. The final model (Model F) attempts to cut any link between the lagged version of the dependent variable and each current time point by estimating that lagged version from the values of other lagged variables as explained earlier.

In these models, we once again see how including a lagged dependent variable reduces the magnitudes of other effects. But in Table 2 this reduces the sizes of coefficients that are implausibly large in Model D to coefficients of more reasonable magnitude in Models E and F. Nevertheless, effects of all the independent variables are significant in each of the three models. Models E and $\mathrm{F}$ are to be preferred, however. Not only do they include a variable (past turnout) that is called for theoretically, but also their coefficients are of much more plausible magnitude, according closely with effects for the same variables found in past research. Even more importantly, both models are well behaved, having no significant autocorrelation or heteroskedasticity problems (as shown by the coefficients at the foot of the table). ${ }^{27}$

\section{Assessing the Findings}

It is satisfying to find such consistent estimates from four models (all but models A and D) that, while each of them is theoretically and methodologically defensible, employ quite different methods for dealing with over-time 
Table 2 Three models explaining turnout in 22 countries, 1945-1999, using fixed-effects regression (standard errors in parentheses)

\begin{tabular}{|c|c|c|c|}
\hline Variable (range of values) & $\begin{array}{l}\text { Model D } \\
\text { Basic }\end{array}$ & $\begin{array}{c}\text { Model E } \\
\text { Basic with lag }\end{array}$ & $\begin{array}{c}\text { Model } F \\
\text { Instrumented lag }\end{array}$ \\
\hline Time since previous election $(0-7)$ & $0.53(0.17)^{* * *}$ & $0.64(0.16)^{* * *}$ & $0.61(0.17)^{* * *}$ \\
\hline Short term majority status $(0-17)$ & $-0.50(0.12)^{* * *}$ & $-0.41(0.11)^{* * *}$ & $-0.38(0.12)^{* * *}$ \\
\hline Short term margin of victory $(0-10)$ & $-0.43(0.14)^{* * *}$ & $-0.35(0.13)^{* *}$ & $-0.42(0.13)^{* * *}$ \\
\hline Short term mean margin $(0-10)$ & $-0.70(0.25)^{* *}$ & $-0.57(0.24)^{* *}$ & $-0.46(0.24)^{*}$ \\
\hline Short term cohesiveness $(0-0.6)$ & $9.42(2.79)^{* * *}$ & $7.04(2.69)^{* *}$ & $6.22(2.87)^{*}$ \\
\hline Cumulative compulsory voting ( -1 to 0$)$ & $17.96(2.97)^{* * *}$ & $11.25(2.91)^{* * *}$ & $12.48(3.18)^{* * *}$ \\
\hline Cumulative executive responsiveness $(-1$ to +2$)$ & $7.68(0.90)^{* * * *}$ & $4.05(0.97)^{* * *}$ & $4.85(1.17)^{* * *}$ \\
\hline Cumulative female empowerment $(0-0.5)$ & $8.77(3.01)^{* *}$ & $5.00(2.84)^{*}$ & $5.99(3.12)^{*}$ \\
\hline Cumulative electorate size (millions) & $-0.06(0.01)^{* * *}$ & $-0.04(0.01)^{* * *}$ & $-0.05(0.01)^{* * *}$ \\
\hline Cumulative proportion of young initiation ( 0 to 0.82 ) & $-4.77(1.04)^{* * *}$ & $-3.81(0.97)^{* * *}$ & $-3.74(1.00)^{* * *}$ \\
\hline Previous turnout $(41-98)^{\mathrm{a}}$ & & $0.41(0.06)^{* * *}$ & $0.32(0.09)^{* * *}$ \\
\hline Constant & $85.78(2.59)^{* * *}$ & $50.95(5.39)^{* * *}$ & $58.26(8.09)^{* * *}$ \\
\hline$N$ of cases & 334 & 334 & 312 \\
\hline$R^{2}$ & 0.66 & 0.81 & 0.80 \\
\hline Breusch-Godfrey autocorrelation test (3 df) & $10.40 * * *$ & 0.19 & 0.30 \\
\hline Arch test for heteroskedasticity $(3 \mathrm{df})$ & $12.86^{* * *}$ & 1.52 & 1.29 \\
\hline
\end{tabular}

${ }^{a}$ Previous turnout is instrumented in Model F, using all other independent variables measured at the previous election. Note: Significant at $* 0.05 ; * * 0.01 ; * * * 0.001$ (one-tailed). 
dependencies and country differences. ${ }^{28}$ Importantly, the deficiencies of each procedure are seen to be unproblematic in this research, since other procedures with different deficiencies give roughly the same results. In particular, removing country differences by including dummy variables for each country in the analysis is found to give almost identical results to those obtained when country differences are removed by taking each variable as a deviation from its country mean. Both techniques produce well-behaved models, free of significant heteroskedasticity or multicollinearity problems. But the inclusion of country dummies clearly inflates the variance explained and would make it problematic for us to use the equation to estimate turnout in any given country (as we will be doing later in this paper). Within any given country, of course, the country dummies are constants and would be dropped from the analysis.

For this and other reasons the model we prefer (and will use in subsequent analyses) is Model E from Table 2. This model is based on more cases than Model $\mathrm{F}$ (which loses one additional case from each country in instrumenting past turnout) but nevertheless explains more variance. It also yields coefficients that (when they differ from those in Model F) are generally closer to the coefficients in Model C. Note that absentee voting was found significant in models A and B but not in Model C. It is omitted from all the models in Table 2 because, although its coefficient was sometimes more than 1.6 times its standard error (the threshold of significance for one-tailed tests), it always had the wrong sign (as it does in Model C). Absentee voting, though it appears to distinguish between countries with higher and lower turnout (as has also been found in past research) does not appear to cause turnout to rise when it is introduced into a country that previously did not provide for absentee ballots. To the contrary, the introduction of postal ballots appears to be associated with falling turnout, quite contrary to expectations. We will return to this finding below.

With this one exception, models that estimate their effects uniquely on the basis of over-time variation (models $\mathrm{C}, \mathrm{E}$, and $\mathrm{F}$ ) produce coefficients broadly comparable to those of a model that includes country differences in the variance to be explained (Model B). Omitting absentee voting from Model B changes the other coefficients hardly at all (not shown) which tells us that a fixed effects model can adequately explain country differences, though the reverse is not true. ${ }^{29}$

Model $\mathrm{E}$ tells us that changes in the character of elections cause turnout to vary markedly. An election that occurs 3 years early will see turnout 2 percentage points lower, on average, $(0.64 \times 3)$ than an election that follows a Parliament that runs to term. ${ }^{30}$ An election in which the largest party is 10 percentage points smaller or in which the margin of victory is 10 percentage points greater will see turnout drop by about 4 percentage points $(0.41 \times 10$ or $0.35 \times 10){ }^{31}$ In a plurality (FPTP) election, if average margin of victory 
increases by 10 percentage points, turnout will drop by 5.7 percentage points. ${ }^{32}$ A country with compulsory voting will see turnout more than 11 percentage points higher and one with a cohesive party system will see turnout 7 percentage points higher than a country without compulsory voting or with a party system in which party discipline is poor. ${ }^{33}$ Finally, a country with an executive that is fully responsive to shifting majorities in the legislature will see turnout that is a whopping 16 percentage points higher $(4 \times 4.1)^{34}$ than one in which the executive is totally unresponsive.

As already mentioned, the model does contain an anomalous finding. Contrary to $\mathrm{H} 4$, time since the previous election shows significant effects for the uninteracted original variable rather than for a short-term or long-term version. This finding, though unanticipated, does make substantive sense. There are a number of circumstances that could cause people not to vote, which we generally see as random and unmeasurable. These include illness and obligations of various kinds that might take up all of a particular day. Such obligations can often be pushed to one side for an overriding reason such as the need to vote on that same day (just as a sick person might be willing to leave the hospital if the occasion seemed pressing enough). However, the more frequently this occurs the less overriding the need to vote may well appear, compared with other obligations, and the likelihood that any particular person will find themselves in such a situation will not relate to whether they are new or established voters.

Let us now turn to the question of the lowering of the voting age. A skeptic might suggest that any division of the dataset into an earlier and a later component would produce a significant effect, and that the findings for young initiation merely reflect the fact of declining turnout that is so ubiquitous in contemporary established democracies. In fact the best test of the young initiation thesis does not come from the analysis conducted in this paper, but from the cohort-level analysis conducted in Franklin and Wessels (2002) and the individual-level analysis conducted in Franklin (2004). Nevertheless, it should be pointed out that the young initiation variable does not split the dataset into two at the same point in time for each country. The split occurs at the point at which the voting age was lowered — as early as 1966 in Germany and as late as 1995 in Austria. Because the young initiation variable is countryspecific, it should (if the theory on which it is based is correct) do a better job of explaining turnout change than any split of the dataset into earlier and later parts. As a test we split the data into pre-1970 and post-1970 parts, a split that should give maximum power to the resulting variable to index the fall in turnout that occurred so ubiquitously after 1970 . When this variable is used in lieu of young initiation in Model E, it fails to achieve significance, and variance explained drops from $81.3 \%$ to $80.4 \%$. So young initiation gains power from being tailored to the specific dates at which the voting age was lowered in 
different countries making it hard to imagine that its effects are spurious, even leaving aside other evidence. The coefficient of 3.8 in Model $\mathrm{E}$ implies that by the time all cohorts have died off that entered the electorate prior to the lowering of the voting age, turnout will have dropped by 3.8 percentage points.

The effects of female empowerment are significant in Models C-F. In Model $\mathrm{E}$ the effect of $5 \%$ suggests that female turnout had risen this much, in percentage points, on average by the time all women had enjoyed the opportunity to vote during their first three elections. This effect is probably underestimated because it is based mainly on the residual gender differences that long postdate the enfranchisement of women in most countries.

\section{Omitted Variables}

As we have seen, only 10 substantive variables prove significant in Model E. Yet the turnout literature has suggested a score or more of variables expected to affect turnout levels. Variables proposed in past research that impinge on the character of elections were listed earlier in this paper. All of them were tested for inclusion in our models, although some failed to prove significant. Those that did not survive preliminary tests comprise average district magnitude, disproportionality, decisiveness of the political system, polarization of the party system, the proportion of the electorate made up of new voters, and whether the government of the day was a coalition government.

Table 3 shows the effects of each of these variables in turn when added to (a sometimes modified) Model E. ${ }^{35}$ Additionally, electoral system type is tested in this table because it has been proposed in past research, even though it was not hypothesized to add significantly to the more elaborate specification of the character of elections employed in this paper. These variables were each operationalized in at least two ways, and Table 3 displays the effect (generally the short-term effect) that proved the more powerful. In the case of absentee voting, weekend voting, and disproportionality, however, long-term versions proved more potent.

As can be seen, none of these variables proved significant when added to Model E. ${ }^{36}$ However, they often fail to prove significant not because they play no role in voter turnout, but rather because their role is subsumed in the operation of other variables. As one example, electoral system type is subsumed in mean margin of victory, which only comes into play for countries with majoritarian electoral systems. Countries with proportional representation are coded 0 on this variable, matching the code that would be given to a majoritarian country in which the race in virtually every district was too close to call. 
Table 3 Effects of further aspects of the character of elections when added, one at a time, to Model E (standard errors in parentheses)

\begin{tabular}{lr}
\hline Independent variable & \multicolumn{1}{c}{ Effect } \\
\hline Independent variable as a cumulative factor & \\
Absentee voting & $-1.52(1.19)$ \\
Disproportionality & $-1.21(1.33)$ \\
Weekend voting & $-1.69(1.21)$ \\
& \\
Independent variable as a short-term factor & \\
Average district magnitude (1-328) & $-0.03(0.02)$ \\
Coalition government & $1.95(1.47)$ \\
Decisiveness of elections & $1.55(4.03)$ \\
Majoritarian electoral system & $-7.50(5.19)$ \\
New cohorts proportion & a \\
Polarization of the party system & $-2.50(4.49)$ \\
\end{tabular}

${ }^{\mathrm{a}}$ New cohorts proportion displaced size of registered electorate when included in Model E.

Note: None of the coefficients are significant at the 0.05 level, one-tailed.

Finally, we should consider how to interpret the difference in variance explained between the models in Table 1 and those in Table 2. Our preferred model (in Table 2) explains considerably less variance (81\%) than the models in Table 1 that included previous turnout (91.5 and 94\%). The difference matters because the implication that flows from explaining over $90 \%$ of variance is that there can be little room for any other effect that would contribute substantively to our understanding of the phenomenon under study. With an additional $10 \%$ of variance unexplained, it might seem possible to improve the model.

Much of the improvement in Models B and C over Models E and F is illusory. It comes from the fact that country differences in Models B and $\mathrm{C}$ are included in the variance to be explained, and country differences are very well explained by turnout at the previous election. When variables are viewed as deviations from country means we remove the variance that is easiest to explain. So the fact that we explain even $81 \%$ of the over time variation in turnout within countries is impressive. But there is certainly room for improvement. The high variance explained in Models B and C (Table 1) is partly illusory and it is quite possible that subsequent research will improve on the models presented there.

\section{Understanding Turnout Decline}

Despite this, the findings of this paper go far towards demonstrating the implications for turnout change of the distinction we have made between short- 
term and cumulative effects on turnout. By taking into account the sizes of new cohorts, we can measure short-term effects of variables whose values change too frequently to have long-term consequences. By keeping track of the cumulative proportion of the electorate that has had the opportunity to be affected by permanent changes in the character of elections we can additionally measure those variables' cumulative effects. ${ }^{37}$

Four variables having to do with electoral competition have short-term effects: size of largest party (implemented as majority status) margin of victory, mean margin of victory (for majoritarian countries), and party cohesiveness. Four variables having to do with institutional arrangements have cumulative effects: compulsory voting, female empowerment, young initiation, and executive responsiveness (the last of these is also an aspect of electoral competition). A further variable with cumulative effects is the size of the electorate. Finally, time since the last election has effects both on new and on established cohorts - the only variable to perform better in its untransformed state than when implemented as a short-term or cumulative factor. The importance of electoral competition emphasizes the fact that turnout declines when voters are given less opportunity to affect policy outcomes.

Using variables implemented in short-term and cumulative versions we explain turnout change in established democracies better than in past research that took no account of the short-term/cumulative distinction. ${ }^{38}$

Of considerable interest is the fact that a focus on turnout change somewhat reduces the apparent importance of institutional differences on turnout levels, compared to the implications of previous research. In particular, institutions whose role has been seen as simplifying the voting act and reducing the costs of voting (weekend voting and absentee voting) do not have the significant effects in this research that have been found in previous research. Weekend voting loses significance apparently because its effects in past findings were spurious - the result of analyzing data that compared average turnout across a small number of countries. With an $N$ of only 20 or so cases, spurious findings are easily come by, and weekend voting appears to have been one such. The same is not true of absentee voting. Its cross-country effect appears to be real and is replicated in this research. However, the provision of absentee ballots in a country where they were previously unavailable (or less readily available) does not cause turnout to rise. Perhaps because absentee voting is sometimes introduced as an attempted cure for poor turnout (as in Switzerland in 1995), the circumstances that surround its introduction may vitiate the purpose for which it was introduced. Or its effects may simply be overwhelmed by whatever circumstances were already causing turnout to fall in the country concerned. In such a case, the causal link would be the reverse of what is generally assumed: falling turnout would be leading to the introduction of absentee voting and the negative effect we measure would be picking up this causal link. If this is so, 


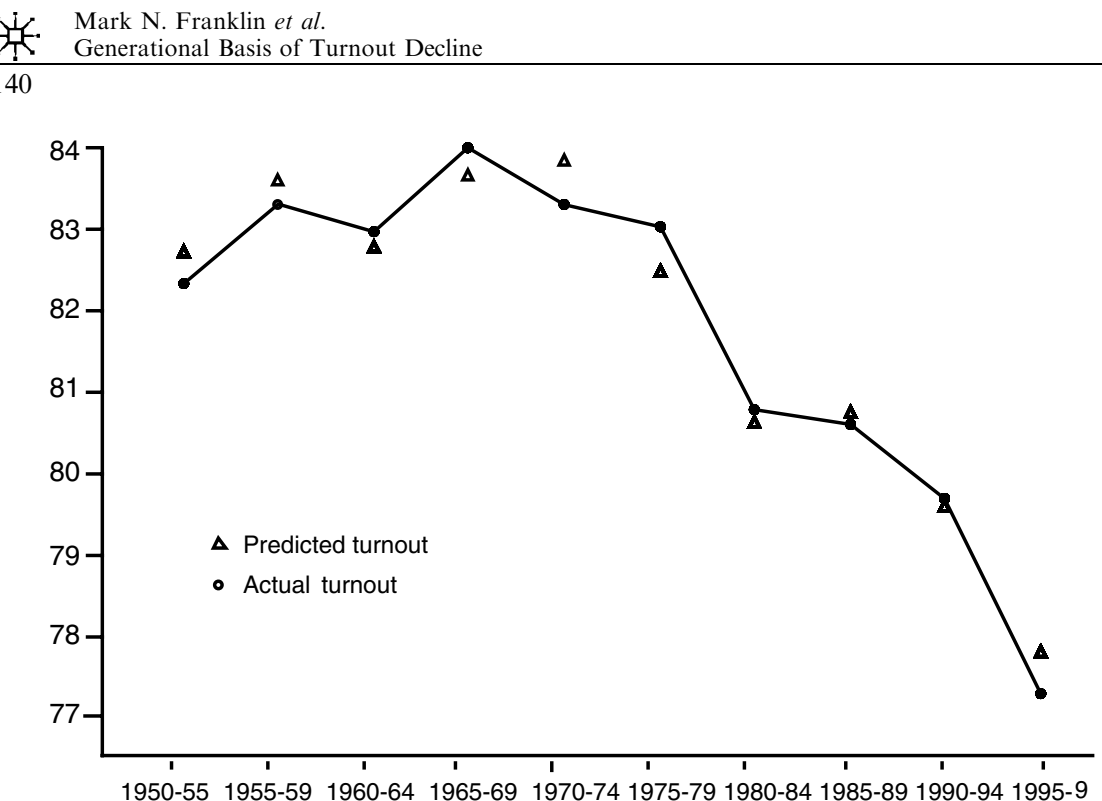

Figure 5 Predicted and actual turnout for 22 countries, 1950-1990s.

then a model that includes absentee voting as an independent variable is badly misspecified. It is for fear that this is indeed the case that we omit the variable from the models in Table 2.

How well does our model explain turnout decline? One way to establish this is to assess the extent to which the average turnout across countries that was shown in Figure 1 is approximated by turnout estimated from the equation corresponding to Model E - plugging in actual values of independent variables for each country. Figure 5 shows that the tracking of actual turnout by estimated turnout is quite good - indeed the match between predicted and actual turnout appears to improve over time, as it should because in the early years our ability to make accurate predictions will have been degraded by irregularities in the cohort structures of several countries, which had varying periods without elections during World War II and before.

Another way to establish this is to look at the extent to which turnout change in particular countries is explained by the model. We mentioned the Netherlands and Switzerland as two countries where commentators have had particular difficulty in explaining turnout change. Figure 6 shows predicted and actual turnout for these two countries. Evidently, the fit is better for Switzerland $(r=0.997)$ than for the Netherlands $(r=0.882)$, where there are effects on turnout that are not captured by our model. But in both cases the predictions show that declining turnout was to be expected on the basis of changes in the character of elections (the abolition of compulsory voting in the Netherlands, the adoption of an executive cartel in Switzerland) that resulted in 

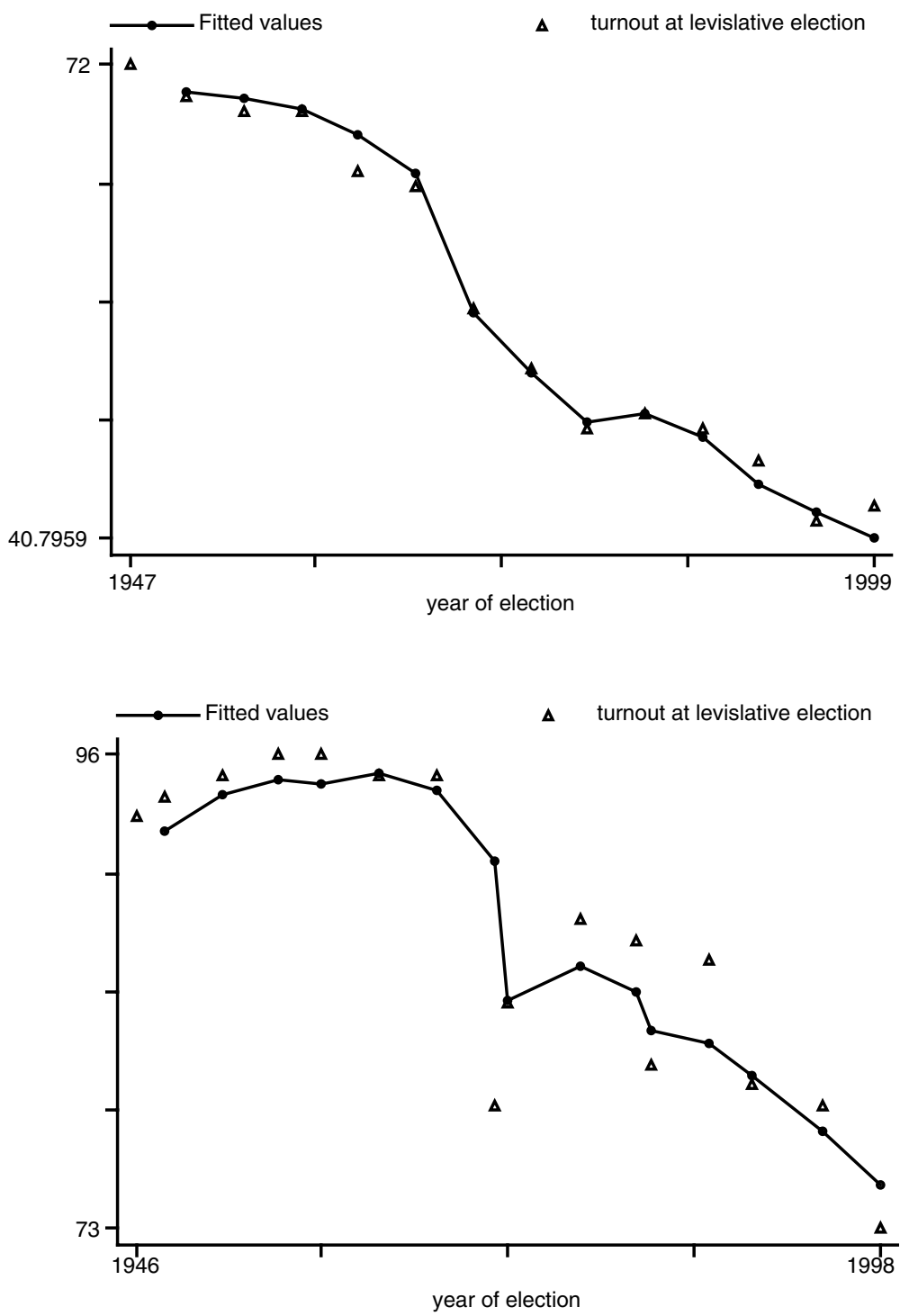

Figure 6 Predicted and actual values of turnout in Switzerland (upper) and The Netherlands (lower).

succeeding generations of voters being socialized into a lower level of turnout (see Franklin (2004) for an elaboration of this story).

What of the remaining 20 countries? Much of the decline in turnout observed in those countries can be explained by the lowering of the voting age. 
We saw in Table 2, Model E, that countries that lowered the voting age can expect to see a drop of 3.8 percentage points in turnout by the time all of those socialized into higher turnout before the lowering of the voting age have left the electorate. This will take 40 years to accomplish, but 30 of those years have already passed, which means that turnout can be expected to have fallen 3 percentage points $(80 \%$ of $3.8 \%)$ in those countries that lowered the voting age (all of those included in our data except for Israel and Japan). Turnout actually fell 3.8 percentage points in these countries during the period, but the discrepancy is easily accounted for by the simple enlargement of the pool of young voters due to the coming of age of the baby boom generation. Since 1970 the size of the electorate under 40 has doubled on average. These young citizens have an average turnout rate $7 \%$ less than the turnout rate for older citizens, only 3 percentage points of which is accounted for by young initiation. A doubling of the portion of the population $(50 \%)$ voting at a rate 4 percentage points lower yields an overall decline of $0.7 \%$, virtually the same as the $0.8 \%$ discrepancy. So the lowering of the voting age, together with the coming of age of the baby boom generation, could essentially account for turnout decline in those countries where it is not accounted for by institutional changes. ${ }^{39}$

\section{Implications}

The findings of this paper strongly suggest the need to take account of generational replacement when investigating turnout change. By taking into account the size of new cohorts, we can measure short-term effects of variables whose values change too frequently to have long-term consequences. By keeping track of the cumulative proportion of each electorate that has had the opportunity to be affected by permanent changes in the character of elections, we can additionlly measure those variables' cumulative effects. The fact that short-term and cumulative effects work better than simple effects of variables employed in past research serves to confirm the primary hypothesis of this paper, that turnout change has a generational basis. Although the underlying theory is quite complex in that it generates separate expectations for short-term than for long-term effects, it has a straightforward rationale connected to the way people learn the habit of voting (or not).

Just as importantly, our strategy for determining the differential impact of different sorts of change on different groups of voters produces a model that persuasively establishes the primacy of electoral competition in influencing turnout levels. Turnout change does not appear to be brought about by changes in the character of society or of its members. When we try to add variables that measure the proportion of university educated or of union 
members, or other features of a society that indicate its citizens' resources or their susceptibility to mobilizing efforts, these variables do not add significantly to variance explained (Franklin, 2004). So commentators seem to be mistaken who see in declining turnout, where it occurs, an indication of unfortunate trends in the composition of society or in the attitudes of its members. Turnout changes, if it does, because elections change their character or because of changes in the proportion of an electorate that pays attention to the character that elections have.

Elections have changed their character in recent years mainly by becoming less likely to bring about policy change. This is what is meant by a less competitive election. At the same time, more voters now respond (because younger voters are less set in their ways) to the fact that there is little reason to vote in an uncompetitive election. In becoming younger, our electorates have also become more aware of what is at stake for them in any given election - a new take on the supposed lack of civic engagement of younger cohorts. If young voters today appear less engaged than in earlier generations, this is partly because they are called upon to vote at a younger age than previously (and thus to pay higher costs of voting) and partly because they are less inclined to pay those costs in circumstances that give their votes less meaning.

\section{References}

Achen, C. (2000) 'Why lagged dependent variables can suppress the explanatory power of other independent variables', Paper Presented at the Annual Meeting of the Political Methodology Section of the American Political Science Association.

Banks, A.S. (ed.) (1997) Political Handbook of the World, New York: McGraw-Hill.

Beck, N. (2001) 'Time-series-cross-section data: what have we learned in the past few years?', Annual Review of Political Science Association 4: 271-293.

Beck, N. and Katz, J. (1995) 'What to do (and what not to do) with time-series-cross-section data', American Political Science Review 89: 634-647.

Blais, A. (2000) To Vote or Not to Vote: The Merits and Limits of Rational Choice Theory, Pittsburgh, PA: University of Pittsburg Press.

Blais, A., Gidengil, E., Nevitte, N. and Nadeau, R. (2001) 'The Evolving Nature of Non-Voting', Paper delivered at the Annual Meeting of the American Political Science Association.

Blais, A., Gidengil, E., Nevitte, N. and Nadeau, R. (2004) 'Where does turnout decline come from', European Journal of Political Research 43: 221-236.

Blondel, J., Sinnott, R. and Svensson, P. (1998) People and Parliament in the European Union, Oxford: Oxford University Press.

Boeckel, R. (1928) Voting and Non-Voting in Elections, Washington, DC: Editorial Research Reports.

Burnham, W. (1965) 'The changing shape of the American political universe', American Political Science Review 59: 7-28.

Butler, D. and Stokes, D. $(1969,1974)$ Political Change in Britain, London: Macmillan.

Campbell, A., Converse, P., Miller, W. and Stokes, D. (1960) The American Voter, New York: willey. 
Christy, C. (1987) Sex Differences in Political Participation: Processes of Change in Fourteen Nations, New York: Praeger.

Cohen, J. and Cohen, P. (1983) Applied Multiple Regression Analysis for the Behavioral Sciences (2nd edn), Hillsdale, NJ: Lawrence Erlbaum Associates.

Crepaz, M. (1990) 'The impact of party polarization and postmaterialism on voter turnout', European Journal of Political Research 18: 183-205.

Dalton, R. (1999) 'Political Support in Advanced Industrial Democracies', in P. Norris (ed.) Critical Citizens, Oxford: Oxford University Press, pp. 57-77.

Downs, A. (1957) An Economic Theory of Democracy, New York: Harper \& Row.

van der Eijk, C. and Franklin, M. et al. (1996) Choosing Europe? The European Electorate and National Politics in the Face of Union, Ann Arbor, MI: University of Michigan Press.

Erikson, R. and Tedin, K. (1981) 'The 1928-1936 partisan realignment: the case for the conversion hypothesis', American Political Science Review 75: 951-962.

Franklin, M. (1996) 'Electoral Participation', in L. Leduc, R. Niemi, and P, Norris (eds.) Comparing Democracies: Elections and Voting in Global Perspective, Thousand Oaks CA: Sage, pp. 214-233.

Franklin, M. (2001) 'How structural factors cause turnout variations at European parliament elections', European Union Politics 2: 309-328.

Franklin, M. (2002) 'The Dynamics of Electoral Participation', in L. Leduc, R. Niemi, and P. Norris (eds.) Comparing Democracies 2, Thousand Oaks CA: Sage, pp. 148-168.

Franklin, M. (2003) 'Electoral Competitiveness and Turnout: How Voters React to the Changing Character of Elections', Paper delivered at the European Consortium for Political Research Joint Sessions Workshops.

Franklin, M. (2004) Voter Turnout and the Dynamics of Electoral Competition in Established Democracies Since 1945, Cambridge: Cambridge University Press.

Franklin, M. and Ladner, M. (1995) 'The undoing of Winston Churchill: mobilization and conversion in the 1945 realignment of British voters', British Journal of Political Science 25: 429-452.

Franklin, M. and Wessels, B. (2002) 'Learning (Not) to Vote: The Generational Basis of Turnout Decline in Established Democracies', Paper delivered at the annual meeting of the American Political Science Association.

Franklin, M., Mackie, T. and Valen, H. et al. (1992) Electoral Change: Responses to Evolving Social and Attitudinal Structures in Western Countries, Cambridge: Cambridge University Press.

Gosnell, H. (1927) Getting Out the Vote: An Experiment in the Stimulation of Voting, Chicago, IL: University of Chicago Press.

Gray, M. and Caul, M. (2000) 'Declining voter turnout in advanced industrial democracies, 19501997', Comparative Political Studies 33: 1091-1122.

Greene, W. (1990) Econometric Analysis, New York: Macmillan.

Inglehart, R. (1977) The Silent Revolution: Changing Values and Political Styles, Princeton, NJ: Princeton University Press.

Inglehart, R. (1990) Culture Shift in Advanced Industrial Society, Princeton, NJ: Princeton University Press.

Inglehart, R. (1997) Modernization and Postmodernization: Cultural, Economic, and Political Change in 43 Societies, Princeton, NJ: Princeton University Press.

Jackman, R. (1987) 'Political institutions and voter turnout in the industrial democracies', American Political Science Review 81: 405-423.

Jackman, R. and Miller, R. (1995) 'Voter turnout in the industrial democracies during the 1980s', Comparative Political Studies 27: 467-492.

Katz, J. (2001) 'What recent experience has taught us about the analysis of pooled time-series data', Political Analysis 9: 271-273.

Kennedy, P. (1992) A Guide to Econometrics (3rd edn), Oxford: Blackwell. 
Lijphart, A. (1997) 'Unequal participation: democracy's unresolved dilemma', American Political Science Review 91: 1-14.

Lyons, W. and Alexander, R. (2000) 'A tale of two electorates', Journal of Politics 62: 1014-1034.

Mackie, T. and Rose, R. (1991) The International Almanac of Electrol History, Washington, DC:CQ Press.

Maddala, G. (1988) Introduction to Econometrics, New York: Macmillan.

McDonald, M. and Popkin, S. (2001) 'The myth of the vanishing voter', American Political Science Review 95: 963-974.

Merriam, C. and Gosnell, H. (1924) Non-Voting, Chicago: University of Chicago Press.

Miller, W. and Shanks, M. (1996) The New American Voter, Cambridge, MA: Harvard University Press.

Nie, N., Verba, S. and Petrocik, J. (1976) The Changing American Voter, Cambridge, MA: Harvard University Press.

Norris, P. (2001) 'Women's Power at the Ballot Box', in Beetham, D., (ed.) International IDEA Handbook on Democracy Assessment, New York: Kluwer Law International.

Norris, P. (2002) Democratic Phoenix: Reinventing Political Activism, New York: Cambridge University Press.

Parry, G., Moyser, G. and Day, N. (1992) Political Participation and Democracy in Britain, New York: Cambridge University Press.

Patterson, T. (2002) The Vanishing Voter: Public Involvement in an Age of Uncertainty, New York: Knopf.

Plutzer, E. (2002) 'Becoming a habitual voter: interia, resources, and growth in young adulthood', American Political Science Review 96: 41-56.

Powell Jr., G.B. (1980) 'Voting Turnout in Thirty Democracies: Partisan, Legal and Socioeconomic Influences', in R. Rose (ed.) Electoral Participation: A Comparative Analysis, London: Sage.

Powell Jr., G.B. (1982) Contemporary Democracies: Participation, Stability and Violence, Cambridge, MA: Harvard University Press.

Powell Jr., G.B. (1986) 'American voter turnout in comparative perspective', American Political Science Review 80: 17-43.

Putnam, R. (2000) Bowling Alone, New York: Simon \& Schuster.

Putnam, R. (2002) 'Conclusion', in R. Putnam (ed.) Democracies in Flux: The Evolution of Social Capital in Contemporary Society, New York: Oxford University Press, pp. 393-416.

Riker, W.H. and Ordeshook, P.C. (1968) 'A theory of the calculus of voting', American Political Science Review 62: 25-42.

Rose, R. and McAllister, I. (1990) The Loyalties of Voters: A Lifetime Learning Model, London: Sage Publications.

Rosenstone, S.J. and Hansen, J.M. (1993) Mobilization, Participation, and Democracy in America, New York: MacMillan.

Schmitt, H. and Mannheimer, R. (1991) 'About voting and non-voting in the European elections of June 1989', European Journals of Political Research 19: 31-54.

Teixeira, R. (1992) The Disappearing American Voter, Washington, DC: Brookings.

Tingsten, H. (1937) Political Behavior, London: King and Son. Reprinted (1963) Totowa NJ: Bedminster Press.

Verba, S. and Nie, N. (1972) Participation in America: Political Democracy and Social Equality, New York: Harper and Row.

Verba, S., Schlozman, K. and Brady, H. (1995) Voice and Equality: Civic Voluntarism in American Politics, Cambridge, MA: Harvard University Press.

Wattenberg, M. (2000) 'The Decline of Party Mobilization', in Dalton, R. and Wattenberg, M., (eds.) Parties without Partisans, New York: Oxford University Press.

Wattenberg, M. (2002) Where Have All the Voters Gone?, Cambridge, MA: Harvard University Press. Wolfinger, R. and Rosentone, S. (1980) Who Votes?, New Haven: Yale University Press. 


\section{Appendix}

\section{Measuring the size of the electorate at each election}

In order to measure the proportionate share of new cohorts in the electorate of each country at the time of each election, we need to know the size of the electorate at each election. Indeed, we also need to have this figure in order to work out the turnout rate. The total number of votes cast is always reported and this number is as near to being cross-nationally comparable as any statistic in comparative political research. So the numerator in the calculation of turnout is not problematic. The denominator is another matter, and the figure that constitutes the denominator in the calculation of turnout is also the denominator in calculating the proportion of new voters. For most countries this figure is the number of registered voters; but for the United States it is conventional to report turnout on the basis of the voting age population. This is because the United States is unique in having voluntary voter registration with a very large proportion of the population failing to register (France also has voluntary voter registration, but registration rates there are almost as high as in countries where the state takes responsibility for ensuring voter registration). In the United States, at least until recent motor voter legislation, those who did not vote were generally not registered and those who took the trouble to register generally voted (Erikson and Tedin, 1981) - a situation that makes it quite impossible to imagine using US registration figures as a basis for measuring turnout there.

The mismatch between the basis for reporting turnout in the United States and elsewhere creates a problem for comparative electoral research. One solution is simply to omit the United States from comparative analyses, as was done by Blais (2000). Another solution (mainly employed by US scholars) is to recalculate other countries' turnout on the basis of their voting age populations (see especially Lijphart, 1997). This solution, which has a plausible ring, actually has the effect of injecting a great deal of error into comparative measures of turnout. This is because, except in some European countries that keep continuous track of their population size, the voting age population is not measured at the time of an election but is estimated from the most recent census, which could be more than 10 years out of date. In such countries, the accuracy of the projected size of the current voting age population will vary greatly from election to election in the same country (depending on how recently a census was conducted) and even more so from country to country (depending on how accurate the census was and how much side information exists on which to base projections). The United States, which has much need for accurate population statistics, may be relatively well equipped to employ the voting age population as a basis for calculating turnout. For most other countries, the estimates would not be official estimates but estimates made by 
individual researchers using assumptions that could give quite different results from those that would be obtained by other researchers using other assumptions. So the most accurate figures for the denominator that we need both for calculating turnout and for calculating the proportionate size of new cohorts are in fact not comparable: VAP for the United States; registered voters elsewhere.

For a small number of countries, as already mentioned, accurate population figures are available at the time of each election. However, using these figures would result in measurement incompatibilities between the countries concerned and countries that do not have such figures, while not eliminating differences in measurement for the United States which, however much effort it puts into making them, still only has estimates of population size, not actual counts. By using registered electorates as the denominator everywhere except the United States, we limit our problems of comparability, needing to adjust the figures for only one country.

Happily a great deal of effort, mainly by Walter Dean Burnham (1965 and personal communications with the authors of the International Almanac of Electoral History), has been put into correcting US estimates of voting age population to remove those not in fact eligible to vote. These corrections have been incorporated into the source employed here, the already mentioned International Almanac of Electoral History (Mackie and Rose, 1991, with updates in the annual data issues of the European Journal of Political Research). There are still reasons to be cautious about interpreting US turnout (and electorate) figures as fully comparable with those published for other countries, but this source certainly incorporates less error than other sources. $^{40}$

\section{Measuring the proportion of the electorate that is new at each election}

Ideally, one would like to be able to find out from census data the exact size of the cohort that is new at each election. On the basis of this figure, the size of the newest three cohorts could be established by simple addition. However, it is not in fact possible to get these figures in comparable terms from census data for 22 countries because the categories used for reporting census figures differ from country to country and change, even in particular countries, with the passage of time. To make matters worse, census data are not reported on the same basis as voting data. Most countries report turnout statistics in terms of the registered electorate; only the United States reports turnout in terms of the voting age population, as already explained. However, census data relate to the voting age population, not the electorate.

For the analyses conducted in this paper, the proportion of the population that is new in each election is computed from the figures we have for the sizes 
of electorates (Mackie and Rose, 1991, and updates). The procedure is straightforward. Survey data from six countries tell us that the average length of time that an individual remains in the electorate of an advanced democracy is 50 years (Franklin and Wessels, 2002) and that this has not changed since the 1960s. It follows that each year 1/50th of the electorate will have had to be replaced if an electorate of constant size was to be maintained (1/47th prior to the lowering of the voting age). At the time of each election, it is a matter of public record how many years (and parts of years) have elapsed since the previous national election. Time elapsed in years multiplied by $1 / 50$ th of the electorate at the previous election yields the number of new members required to maintain a constant size electorate. To this figure needs to be added (subtracted if negative) any difference in size between the electorate at the previous election and the electorate at the current election in order to take account of variations over time in birth and death rates. The sum is an estimate of the total number of individuals newly enfranchised at any given election. Dividing the sum into the figure for the total electorate at the election concerned yields the proportion of the electorate that is contained in the incoming cohort. Adding up the figures for three successive elections before dividing the sum into the electorate size for the last of the three elections yields the proportion of that electorate facing one if its first three elections. ${ }^{41}$

\section{Notes}

1 The countries are Austria, Belgium, Britain, Canada, Denmark, Finland, France, Germany, Iceland, Israel, Italy, Japan, Luxembourg, Malta, The Netherlands, New Zealand, Norway, Switzerland, Sweden, and the United States. Earlier versions of this paper were presented at the American Political Science Association annual meeting, 2000; at the European Consortium of Political Research First Congress, 2001; and at the International Political Science Association World Congress, 2003. We are grateful to panel participants at those three meetings for helpful comments, and even more so to this journal's referees.

2 Turnout has risen at several recent elections, including the US Presidential election of 2000, the German federal election of 1998, the Swedish and Dutch national elections of 1994 and the British general election of 1992.

3 The dominance of education and social status has not been found ubiquitously outside the United States.

4 The mobilization model, of course, serves to some extent to bridge the gap between the two.

5 We include Malta despite the suspension of its constitution in 1958 because this only created a gap of 2 years longer than that country's normal 5-year gap between elections.

6 In a groundbreaking article, Plutzer (2002) looks at persistence and inertia in the propensity to turnout, a different take on the same concerns that we address here.

7 In some ways, this could be seen as a change in the character of the electorate rather than in the character of elections, but the important thing is the way in which individuals experience elections. At a younger age the experience will have generally been less likely to lead to the habit of voting. 
8 Tingsten (1937) found that female enfranchisement in Scandinavian countries gave rise to female turnout that was initially $10-12 \%$ less than male turnout, equivalent to a $5-6 \%$ drop in overall turnout.

9 It has been proposed that larger countries will see lower turnout because each vote counts for less (Blais, 2000). However, controlling for electorate size in a longitudinal analysis (as conducted here) also controls for changes in the age structure of the electorate, because a large influx of young voters will register as an increase in the size of the electorate, providing a control for generational effects. The proportion of the electorate made up of new voters provides a more specific control for generational effects.

10 This variable is a weighted average of turnout at the previous election with turnout at the election before that, giving twice as much weight to the more recent election. Very similar results are obtained if turnout $t_{t-1}$ and turnout $t_{t-2}$ are used together as separate measures of past turnout. In order not to lose the second election in each series (in addition to the first), past turnout for the second election in each country is set to turnout $t_{t-1}$.

11 Electorate size and average district magnitude are particularly hard to code as long-term factors, since increases, where they occur, are often followed by further increases. So the cumulative effect of these variables has to be a sum weighted not only by the size of the group affected by each change but also by the extent of each change.

12 Cohesion is classified as a short-term factor even though it changed its values less frequently than this (see below).

13 See Franklin (2004, Appendix B).

14 Our findings in this paper, depending as they do on aggregate-level effects, are subject to the possibility of ecological fallacies. Yet because different predictions are made for different variables, depending on the nature of the long-term effects we theorize (as illustrated in Figures 2-4), it would be remarkable if these different predictions were all of them confirmed as a result of some other process. In Franklin (2004), the aggregate-level findings are checked as far as possible by individual-level and cohort-level analyses that find the same effects for variables that the different analyses have in common (see also Note 15).

15 When considering an institutional change, this is the information a politician would need: the ultimate effect of the change once generational replacement has removed those not affected by the reform. Such inferences are of course subject to the possibility of ecological fallacies just as are our findings (see Note 14). So, for example, effects attributed to new cohorts could in reality result from reactions among other cohorts to the influx of new voters. Although such reactions are implausible in the light of past findings about the relative immobility of turnout among established cohorts, in Franklin (2004) the inferences mentioned in the text are checked and validated by the use of individual-level and cohort data, as explained in Note 14.

16 The reason some variables are scaled with negative values is because values of 0 cannot be weighted by the proportion of the electorate affected by a change to that value (see below).

17 We halve the proportion of new voters in order to derive an estimate of this proportion. The resulting interaction is analogous to a count of the number of years since female emancipation (though scaled very differently), the measure used by Norrris (2001) in research that has similar hypotheses regarding female emancipation to those put forward here. Note that this hypothesis runs counter to common assumptions about female turnout originating with Tingsten (1937), but recent research has not supported these assumptions. For an overview of such research, see Norris (2001).

18 Because a large role in our model is played by inertia, any large non-random variations in turnout at previous elections will be reflected in our estimate of turnout at the current election. So we will tend to predict more variance in countries that have more variance - exactly what a good model should do. Whether this feature of our models succeeds in overcoming the 
heteroskedasticity problem is an empirical question that will be addressed with appropriate diagnostic tests.

19 Because the regression procedures we employ explain variance on different bases, for the sake of comparability the variance explained in our tables is always the square of the correlation between actual turnout and turnout predicted by each model.

20 Whether the cases are considered separate or part of a time series is simply a matter of how they are analyzed. We deal with the same 356 cases either way.

21 To test the robustness of our models, a large number of different model specifications were cycled through and, where choice of specification appeared to make a difference, those differences are reported.

22 As an experiment, compulsory voting countries (Belgium, Luxembourg and Italy) were excluded from the list of those that extended the franchise, on the grounds that compulsory voting would have forced women to vote as soon as they were enfranchised; however, a variable that coded these countries as countries in which the franchise was extended performed better.

23 Operationalizations of variables employed in this paper are to be found in Franklin (2004, Appendix B).

24 It was not possible to include all of these variables in a single analysis because multicollinearity between different versions of the same variables resulted in none of them proving significant (in Table 3, we show the effects of other independent variables when brought into the model one at a time). For the same reason, it was not possible to include interaction terms along with uninteracted versions of the component variables. So the model specifications used here are somewhat unconventional. In Franklin (2004), the findings are checked by employing properly specified models at the individual and cohort levels where larger data sets made it possible to overcome some of the problems found in the analyses reported here.

25 These are not reduced-form models, for reasons explained in Note 24. See Table 3 for effects of other independent variables.

26 The dummy variables have the effect of adjusting the intercept to suit individual countries so that differences in mean turnout by country do not bias the parameter estimates for named independent variables. These adjustments are of no substantive interest and so are not reported.

27 Multicollinearity also turns out to be unproblematic. The regression of all the other independent variables on each one of them in turn yields a set of multiple correlations of which none come close to the multiple correlation between all independent variables and the dependent variable (Kennedy, 1992, 181).

28 Additional models were evaluated that included interaction terms for different sorts of electoral systems, on the assumption that variables might have different effects in proportional than in majoritarian systems. None of these models worked as well as the models presented here, although there were strong indications that the effects of female empowerment were greater in majoritarian systems.

29 Panel corrected standard errors are not calculated in a fixed-effects analysis, but the fact that there is no significant heteroskedasticity in Models E and F implies that the separate country panels are not sufficiently different as to require panel corrected standard errors, provided past turnout is included in the model. This is also implied by the fact that the standard errors calculated in Model C, where they are panel corrected, are very similar to those calculated in Model E, where they not. If anything, standard errors are slightly larger (and thus more conservative) in Model E.

30 Terms in different countries are not the same, of course. Our findings suggest that countries with 5 -year parliamentary terms will see turnout two-thirds of a percent higher than countries with 4year parliamentary terms, other things being equal.

31 Remember that majority status is coded as the gap between the largest party's size and $50 \%$. The larger the gap the less influence the party will have on policy, so the effect is negative. 
32 The interaction between margin and mean margin is even more powerful, indicating that people are even more likely to vote in a cliff-hanging district if the result is likely to affect the balance of forces in the legislature, and the interaction raises the variance explained in Model $\mathrm{E}$ to 0.83 . However, because the coefficient is hard to interpret we do not include this higher order interaction in the findings.

33 This variable is a rather crude measure derived from the Banks data. Most countries are coded as cohesive, but the United States, Switzerland, Japan, Italy, and Belgium between 1961 and 1977 are coded as not cohesive. The coding only changes over the course of the half century for Belgium, but for that country it changes twice: from cohesive to uncohesive and back again. Because of that double change, the variable is classified as having short-term effects (the period during which Belgium is rated uncohesive is longer than three elections but too short to have permanent effects on more than a small fraction of the electorate). An alternate coding that treated cohesion as a long-term factor did not have significant effects. However, the fact that more than the normal $3 / 50$ ths of the electorate will have been affected by these changes will have produced a larger coefficient than would have been produced had the two Belgian changes occurred closer together. The real effect of party cohesion is probably more like $5 \%$.

34 This variable is coded on a 4-point scale.

35 The proportion of the electorate made up of new voters replaces electorate size when it is included in Model E (or any other model).

36 Additional variables were defined and tested in Franklin (2004) but the results are not presented here for lack of space.

37 Again we should make provisos regarding the possibility of an ecological fallacy (see notes 14 and 15).

38 Without taking account of the short-term/cumulative distinction, Gray and Caul (2000) explained $72 \%$ of the variance in a data set consisting of 18 of the countries studied here over a slightly shorter period. When our universe of countries and elections is restricted to match theirs, the variance we explain falls fractionally to $81.1 \%$ but still remains well above theirs. Franklin (2002) explained $71 \%$ of the variance in a data set consisting of rather more countries (31) but over varying periods. The analysis conducted in this paper cannot readily be made comparable with that one because gaps in the series of elections for many of the additional countries make some of our variables impossible to operationalize. Franklin (2004) explained $77 \%$ of the variance with a model containing exactly the same variables as are employed here, over exactly the same elections, but using only uninteracted versions of each independent variable.

39 The accounting we need to go through is actually rather more complicated because a number of other factors among our independent variables also have effects on turnout. See Franklin (2004) for a complete accounting for turnout decline in these countries since 1945.

40 We checked the denominator in our calculation of US House turnout against the figures used by McDonald and Popkin (2001) for correcting their measure of presidential turnout, and recalculated house turnout on the basis of their corrected figure whenever the Mackie-Rose figure differed from theirs. There is no reason to suppose that remaining errors are anything other than random so, to the extent that US turnout is not adequately corrected, this will make it more difficult for us to obtain findings that prove statistically significant - a conservative measurement strategy.

41 This procedure would yield missing data for the first three elections in each country. In order not to lose such a large fraction of the available data, the size of the first three cohorts in each country's second election is estimated by taking three times the estimated number of new potential voters since the first election; the size of the first three cohorts in each country's third election is estimated by adding twice the number of potential voters new in the third election to the number of those new in the second election. 